\title{
Threatened Ethiopian wolves persist in small isolated Afroalpine enclaves
}

Jorgelina Marino

\begin{abstract}
The Ethiopian wolf Canis simensis is endemic to the Afroalpine highlands of Ethiopia. Half of the world population, estimated at c. 500 individuals, lives in the Bale Mountains of southern Ethiopia. Little is known, however, about the presence of wolves and suitable habitat in other Afroalpine ranges. Assessing the distribution, abundance and threats to all extant populations is a conservation priority for this Critically Endangered canid. With these objectives in mind, surveys were conducted between 1997 and 2000 in the little known regions of Arsi, Wollo, Gondar and Shoa. Suitable habitat and resident wolves were found in all regions. Outside Bale the existence of six other isolated populations, including
\end{abstract}

two previously undescribed, was confirmed. All were small, estimated at no more than 50 individuals, and some with $<25$ individuals. Two population extinctions were documented, and habitat loss to agriculture largely explained local extinctions in small habitat patches. While Bale remains crucial for the long-term persistence of this species, the finding of several small and threatened populations highlights the need for in situ conservation actions to be expanded to other regions of the Ethiopian highlands.

Keywords Afroalpine highlands, Bale Mountains, Canis simensis, Ethiopia, wolf.

\section{Introduction}

Ethiopian wolves Canis simensis evolved in the geographical isolation of the Ethiopian massif, and are currently restricted to a few areas of this high altitude ecosystem (Gottelli \& Sillero-Zubiri, 1992; Yalden \& Largen, 1992). Unlike other canids, renowned for their adaptability, they prey almost exclusively on the abundant Afroalpine rodent fauna. It is mainly because of this feeding specialization that they are now at risk of extinction. Categorized as Critically Endangered on the 2002 IUCN Red List (IUCN, 2002), the Ethiopian wolf is the rarest canid in Africa (Sillero-Zubiri \& Macdonald, 1997).

The world population of the Ethiopian wolf has been estimated at c.500, of which about half live in the Bale Mountains of southern Ethiopia (Sillero-Zubiri \& Macdonald 1997; Sillero-Zubiri et al., 2000). Studies in Bale have shown that the abundance and distribution of wolves closely follows that of its main prey (SilleroZubri \& Macdonald 1997; Sillero-Zubri et al., 2000). Further evidence of their dependence on Afroalpine rodents has been provided by data on historical sightings

Jorgelina Marino Wildlife Conservation Research Unit, Zoology Department, University of Oxford, South Parks Road, Oxford, OX1 3PS, UK. E-mail: jorgelina.marino@zoo.ox.ac.uk

Received 10 September 2001. Revision requested 4 March 2002. Accepted 19 September 2002 in Ethiopia (Gottelli \& Sillero-Zubiri, 1992), and recent studies of wolves in the central highlands (Ashenafi, 2001).

Little is known, however, about the presence of the Ethiopian wolf and the extent of suitable habitat for it in other regions. Previous estimates of the species' total population were on the basis of the predicted extent of Afroalpine habitats from topographic maps (Malcolm \& Sillero-Zubiri, 1997, Gottelli \& Sillero-Zubiri, 1992). Populations in the highlands of Wollo were assumed to be extinct, and threats to population persistence outside Bale remained speculative. The political situation prevailing in the 1980s and early 1990s prevented field surveys into the northern highlands.

The Ethiopian wolf action plan (Sillero-Zubiri \& Macdonald, 1997) indicated the urgent need for a complete survey of all areas of potential habitat as a priority for the development of a global strategy to protect the species from extinction. In the face of current trends in habitat destruction and the risks of persecution, disease transmission and hybridization with domestic dogs, the implementation of conservation measures for every major population is crucial for the survival of the species (Sillero-Zubiri, 2000).

Between 1997 and 2000 surveys were organized by the Ethiopian Wolf Conservation Programme (EWCP) to all potential wolf ranges in Ethiopia. Surveys extended to the areas occupied by the species in the past and to all other high altitude ranges in Ethiopia. Standard techniques for rapid assessment were applied to meet 
the following objectives: a) to determine wolf presence/ absence and relative abundance, b) to record any local extinctions and, where possible, their circumstances, c) to map habitat distribution, and d) to assess threats to the persistence of populations. In this paper I present the results of these surveys, provide an updated summary of the distribution and status of $C$. simensis, discuss the threats that the species faces across its range, and provide preliminary guidelines for in situ conservation outside Bale.

\section{Study area}

The Ethiopian massif is characterized by marked altitudinal variations that produce a range of climates affecting plant and animal distributions and the concentration of people (Yalden \& Largen, 1992). Most people live in the fertile highlands of the Woina Dega (warm temperate) and Dega (temperate) zones. The Wurch zone (alpine, $>3,000 \mathrm{~m}$ ) is colder and less favorable for agriculture and broadly corresponds with the distribution of habitats suitable for the Ethiopian wolf (Fig. 1). Within the Wurch, ericaceous heathlands dominated by Phillipa and Erica spp. (Miehe \& Miehe, 1993) are replaced by Afroalpine grasslands, scrubs and meadows above c. $3,200 \mathrm{~m}$.

Field surveys were carried out in the Simien Mountains, Mount Guna, Mount Choke, the highlands of North and South Wollo, Gosh Meda and the Arsi Mountains (Fig. 1). Study sites were selected from historical records, previous surveys, and the identification of high altitude ground from topographic maps (Yalden et al., 1980; Sillero-Zubiri \& Macdonald, 1997; Malcolm \& Sillero-Zubiri, 1997). Detailed descriptions of the itineraries can be found elsewhere (Marino et al., 1999; Ash, 2000).

\section{Methods}

Surveys consisted of short visits to each study site and the use of techniques for rapid assessment (Sillero-Zubiri \& Macdonald, 1997). Surveys were carried out on foot or horseback, and were designed to cover all suitable habitat in each site. Survey teams comprised 2-3 trained EWCP members, a wildlife expert from the relevant Zone's Agricultural Department, and 1-4 guides from the local Peasant Associations. Surveys in each Afroalpine range lasted 2-6 days depending on its area.

\section{Census transects}

Census transects consisted of sections of continuous trekking or horse riding along survey routes, lasting a whole morning or afternoon. Sightings and signs of wolf activity in the form of 'dig-outs' (made by wolves searching for rodents) were recorded. Sequential positions were taken along transects using a Global Positioning System. Transect length varied between 4 and $16 \mathrm{~km}$ and the number of transects varied between 2 and 10 in relation to the size of the study site. For each transect, encounter rates were calculated as the number of sightings (independent of the size of the group observed) and dig-outs observed per $\mathrm{km}$. For each Afroalpine unit (defined below) an average encounter rate was calculated.

\section{Interviews}

Following a standard questionnaire (Sillero-Zubiri \& Macdonald, 1997) local people were asked about the presence of wolves in the area, causes of wolf mortality, perceived population trends, incidence of disease, cases of wolf predation on livestock, and attitudes towards wolves. Interviews were aimed at people who frequently visited the Afroalpine area, either to herd their livestock, collect grass and firewood, or en route to local markets. A total of 103 interviews were carried out, varying between 10 and 32 in the various areas. Interviews were analyzed separately for region. Results, where possible, were calculated as the percentage of respondents giving a positive answer or a specific answer from a set of choices.

\section{Mapping and habitat analysis}

Suitable wolf habitat was mapped along surveys routes and from vantage points. Habitat was hand-mapped over 1:50,000 topographic maps $(1: 100,000$ for Simien and 1:125,000 for parts of North Wollo). Habitat mapping was Global Positioning System-assisted in order to achieve the fine level of detail provided by the topographic maps. Notes were taken on the nature of the lower limit of wolf ranges, whether corresponding with natural features, such as escarpments, or with agricultural fields.

Additionally, habitat quality was mapped on the basis of vegetation types, as described by Gottelli \& SilleroZubiri (1992), who showed that the density of Ethiopian wolves in Bale was negatively correlated with vegetation height and positively correlated with the density of rodent prey (Sillero-Zubiri et al., 1995a, b). On this basis, habitats in the areas surveyed were classified either as 'marginal' or 'good', the latter encompassing both the 'good' and 'optimal' categories of Gottelli \& SilleroZubiri (1992) to reduce subjectivity. Optimal habitat is characterized by Afroalpine meadows with short grass and herbs and a rodent biomass of 3,500-4,000 $\mathrm{kg} \mathrm{km}^{-2}$, good habitat is characterized by Helichrysum scrub and 


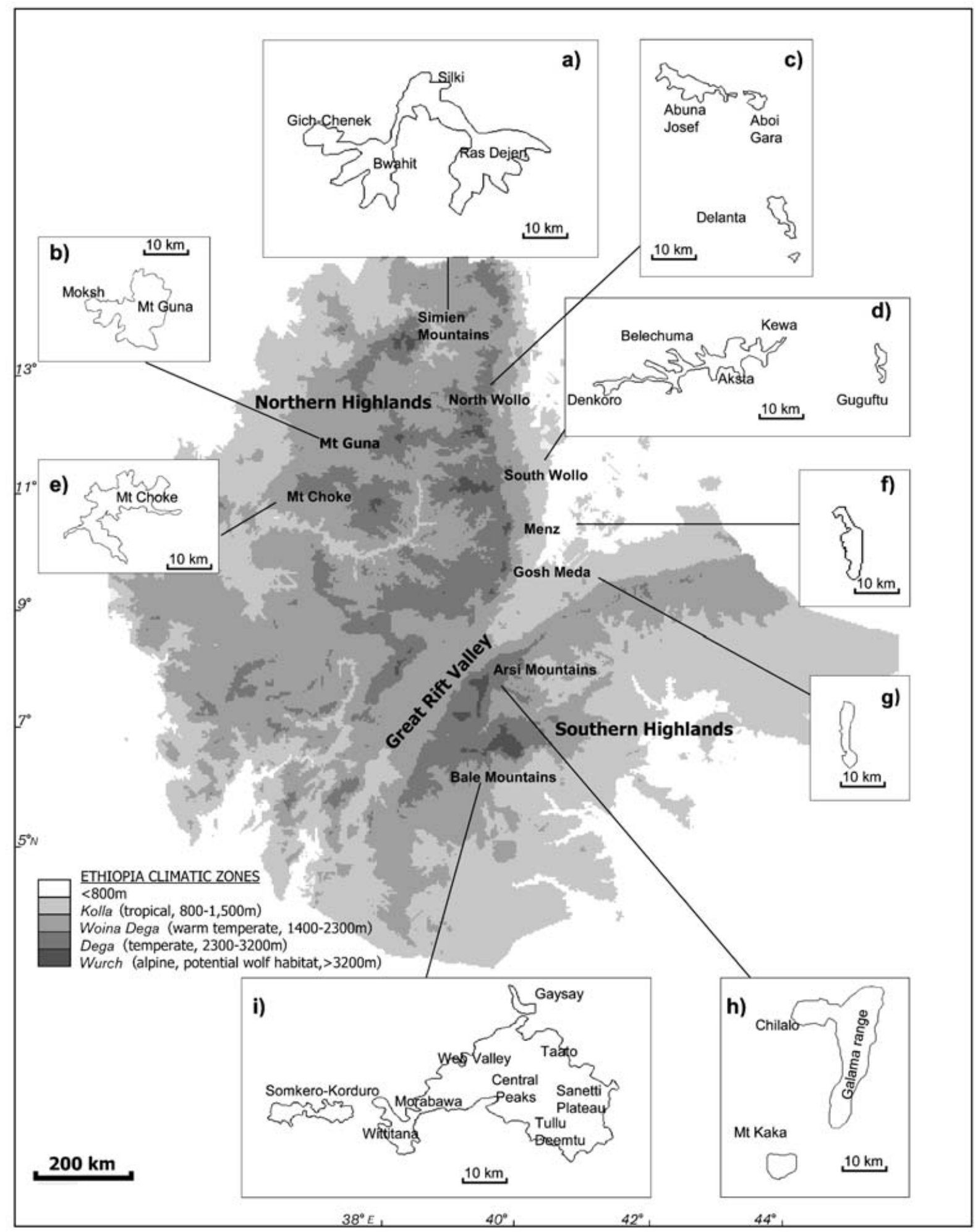

Fig. 1 Afroalpine ranges and remaining wolf habitat in Ethiopia. Climatic zones are illustrated in a gradient of gray. The detailed maps (a to j) illustrate the current distribution of suitable wolf habitats (see text for details). 
montane grasslands with a rodent biomass of one third of optimal habitat, and marginal habitats include dense ericaceous and charanfe (Euryops pinifolius) heathlands, steep slopes and escarpments, rocky barren peaks and overgrazed grasslands near settlements, with a rodent biomass one fifth to one tenth of optimal habitat (Gottelli \& Sillero-Zubiri, 1992).

To calculate habitat areas field maps were digitized with the IDRISI Geographical Information System software (Clark Labs, Clark University, Worcester, USA). Extant wolf habitat was grouped into geographical entities or 'Afroalpine units' (AU). Distances between AUs were larger than the potential dispersal of individual wolves, known to be up to $20 \mathrm{~km}$ (SilleroZubiri \& Gottelli, 1995; Zelealem Ashefani, pers. comm.; Zegeye Kibrit, pers. comm.). It is reasonable to assume that dispersal of individuals between AUs was not occurring at a substantial rate, if at all. Therefore, each unit was assumed to contain an isolated population or metapopulation (c.f. the 'habitat isolates' concept of Morrison et al., 1998).

\section{Population estimates}

Estimate of wolf density and population size could not be derived from the census data. However, attempts to improve previous population estimates were undertaken, using the data on the extent of remaining habitat obtained from the surveys. Known densities of wolves in Bale (Gottelli \& Sillero-Zubiri, 1992) were used to estimate the number of wolves in each AU. Densities were extrapolated to the extent of 'marginal' and 'good' habitat in each AU. To minimize overestimates, the lowest densities recorded in Bale's good (0.2-0.3 wolves per $\left.\mathrm{km}^{2}\right)$ and marginal (0.1 wolves per $\left.\mathrm{km}^{2}\right)$ habitats (Gottelli \& Sillero-Zubiri, 1992) were applied. A range of population sizes were derived as upper value $=\left(\mathrm{km}^{2}\right.$ of good habitat $\times 0.3$ wolves $\left.\mathrm{km}^{-2}\right)+\left(\mathrm{km}^{2}\right.$ of marginal habitat $\times 0.1$ wolves $\left.\mathrm{km}^{-2}\right)$, and lower value $=\left(\mathrm{km}^{2}\right.$ of good habitat $\times 0.2$ wolves $\left.\mathrm{km}^{-2}\right)+\left(\mathrm{km}^{2}\right.$ of marginal habitat $\times 0.1$ wolves $\mathrm{km}^{-2}$ )

\section{Results}

\section{Simien Mountains}

The area of available habitat for wolves in Simien was the largest north of the Rift Valley (Table 1). Steep escarpments limited suitable habitat along north facing slopes. Elsewhere the upper limit of agriculture and encroachment restricted wolf ranges to areas above $3,700-3,900 \mathrm{~m}$ in four main areas and connecting corridors (Fig. 1a). Gich-Chenek, the only area contained within the Simien Mountains National Park, was affected by the construction of a road and newly ploughed fields along its southern border. Bwahit, east of the park, contained the least disturbed habitats. Short grasslands, in parts overgrazed, characterized the habitat in Silki and Ras Dejen. Wolves and wolf signs were recorded in all areas and were most abundant in Bwahit, but average encounter rates for Simien were the lowest of all AUs in which wolves were recorded (Fig. 2). Although most interviewees had seen wolves in the area, many believed the population was declining because of overgrazing and agricultural expansion (Table 2). A positive or indifferent attitude towards wolves was dominant; people from

Table 1 Distribution and extent of suitable wolf habitat in Ethiopia. The potential area is the land above 3,200 $\mathrm{m}$, and the area of remaining habitat was calculated from the field survey maps (see text for details).

\begin{tabular}{|c|c|c|c|c|c|}
\hline Afroalpine unit & $\begin{array}{l}\text { Potential area } \\
\left(\mathrm{km}^{2}\right)\end{array}$ & $\begin{array}{l}\text { Available area } \\
\left(\mathrm{km}^{2}\right)\end{array}$ & $\begin{array}{l}\text { Percentage } \\
\text { remaining }\end{array}$ & $\begin{array}{l}\text { Amount in protected } \\
\text { areas }^{2}\end{array}$ & Spatial structure \\
\hline \multicolumn{6}{|l|}{ North of Rift Valley } \\
\hline Simien Mountains & 960 & 273 & 28 & 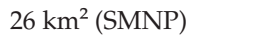 & patches and corridors \\
\hline Mt Guna & 210 & 51 & 24 & & isolated patch \\
\hline Mt Choke & 500 & 134 & 27 & & isolated patch \\
\hline North Wollo & 1,150 & 140 & 12 & & patches and corridors \\
\hline South Wollo & 1,220 & 243 & 20 & c. $20 \mathrm{~km}^{2}$ (DSF) & patches \\
\hline Menz ${ }^{1}$ & 124 & 112 & 90 & $82 \mathrm{~km}^{2}(\mathrm{GCM})$ & isolated patch \\
\hline Gosh Meda & 90 & 20 & 22 & & isolated patch \\
\hline \multicolumn{6}{|l|}{ South of Rift Valley } \\
\hline Arsi Mountains & 1,000 & 870 & 87 & c. $50 \mathrm{~km}^{2}$ (BLHB) & mainland-island \\
\hline Bale Mountains ${ }^{1}$ & 1,990 & 1,141 & 57 & $1,100 \mathrm{~km}^{2}(\mathrm{BMNP})$ & mainland-island \\
\hline Total & 7,220 & 2,984 & 41 & c. $1,278 \mathrm{~km}^{2}$ & \\
\hline
\end{tabular}

${ }^{1}$ Habitat areas from recently updated maps of Bale and Menz (Sillero-Zubiri et al., 2000).

${ }^{2}$ SMNP Simien Mountains National Park, DSF Denkoro State Forest, GCM Guassa Community Management, BLHB Bora Luku Hunting Block, BMNP Bale Mountains National Park 

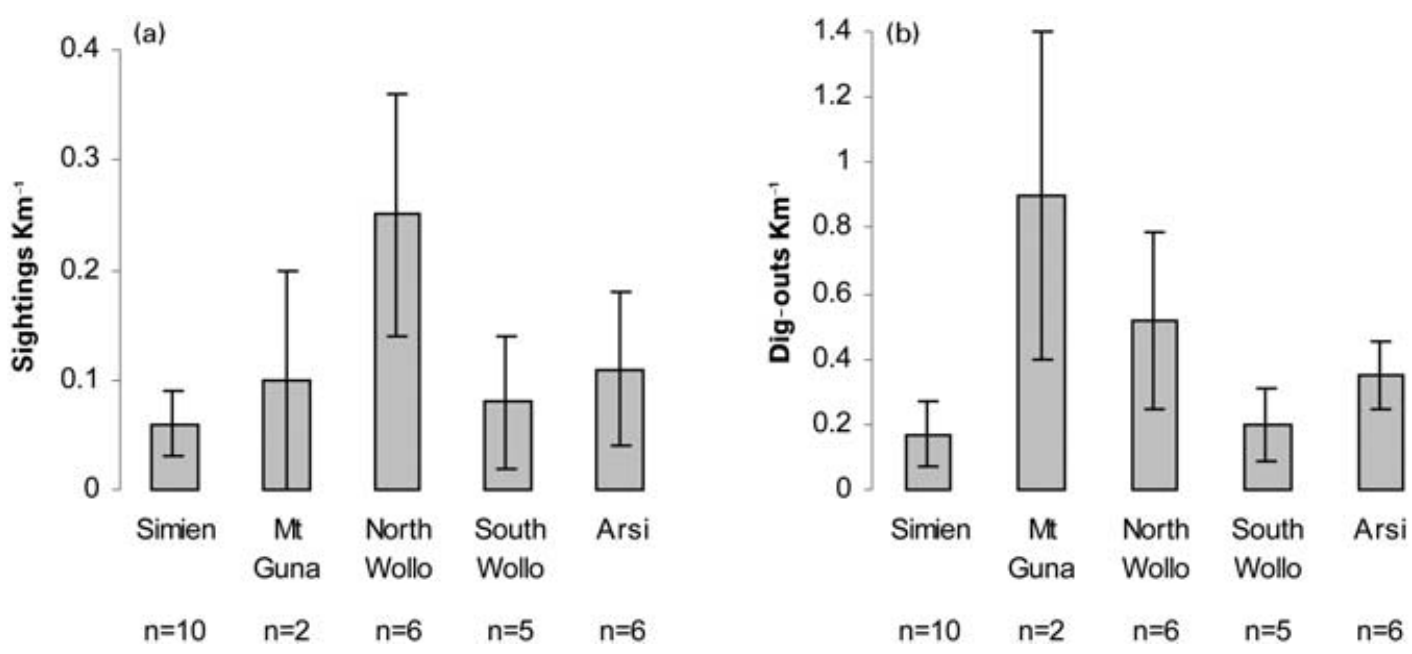

Fig. 2 Mean encounter rate of wolves $( \pm S E)(a)$ and wolf 'dig-outs' (b) along census transects in those Afroalpine units where wolves were detected; $n=$ number of transects.

around the park thought wolves could be beneficial because they attract tourists. Cases of livestock losses to wolves were reported, but common jackals Canis aureus were indicated to be the main predator.

\section{Mount Guna}

Mount Guna was the smallest AU that sustained a resident population (Table 1). This isolated patch was limited to the east by steep escarpments and on its western slopes by newly cultivated fields, human encroachment and degraded pastures at c. 3,650 m (Fig. 1b). The presence of wolves was confirmed by sightings and dig-outs (Fig. 2), concentrated on the central and northern parts of the range. Encounter rate of dig-outs was the highest recorded (Fig. 2). Everybody interviewed had seen wolves in the area, and most perceived that wolves were breeding well and their numbers increasing or stable, although some alleged that human encroachment was negatively affecting the population (Table 2). Attitudes towards wolves were in general positive, and wolf predation on livestock was not perceived as a problem (Table 2).

\section{North Wollo highlands}

The available wolf habitat in North Wollo (Table 1) was discontinuous (Fig. 1c). The Abuna Josef massif was the largest area, loosely connected by narrow ridges with the small Aboi Gara range to the east, in turn separated by approximately $20 \mathrm{~km}$ from the Delanta range in the south. Steep escarpments to the north of Abuna Joseph and east of Delanta limited wolf ranges. Elsewhere, overgrazed meadows and cultivated fields restricted suitable habitat to areas above 3,700-3,800 m, and above
3,450-3,500 m in Delanta. Sightings and signs of wolves (Fig. 2) were recorded in all areas, but they were most abundant in Delanta, where the largest group, with 6 individuals, was observed. Wolf sightings were the highest recorded (Fig. 2). All people interviewed had seen wolves in their area, and many believed that wolves were recovering from past persecution (Table 2). A large proportion of people reported a negative attitude towards wolves, and invoked wolf predation on livestock as the reason. Many reported having lost animals, and perceived wolves as the main predators of livestock.

\section{South Wollo highlands}

Over $240 \mathrm{~km}^{2}$ of suitable wolf habitat were found in South Wollo (Table 1). Agriculture and human settlements extended up to 3,700-3,800 m, except for Denkoro State Forest, created to protect the last remnant of ericaceous forest in northern Ethiopia, where grasslands extended down to 3,200 m. Wolf habitat was distributed along a main massif with narrower ridges heading off to the north and south (Fig. 1d). Vast areas of short grasslands and narrow corridors appeared degraded by overgrazing. In a small patch of suitable habitat in Guguftu, east of the main massif, a commercial sheep farm had been established and the areas was being ploughed for the cultivation of pasture. With the exception of Guguftu, wolf sightings and signs were recorded in all sites (Fig. 2). Most of the people interviewed had seen wolves, but only a third of them within the last year (Table 2), and most believed wolves were declining as a result of the pastures being overgrazed. Reported sightings in Guguftu were 5-10 years old, and past persecution was considered the main cause of this local extinction. People were mostly indifferent to wolves. 


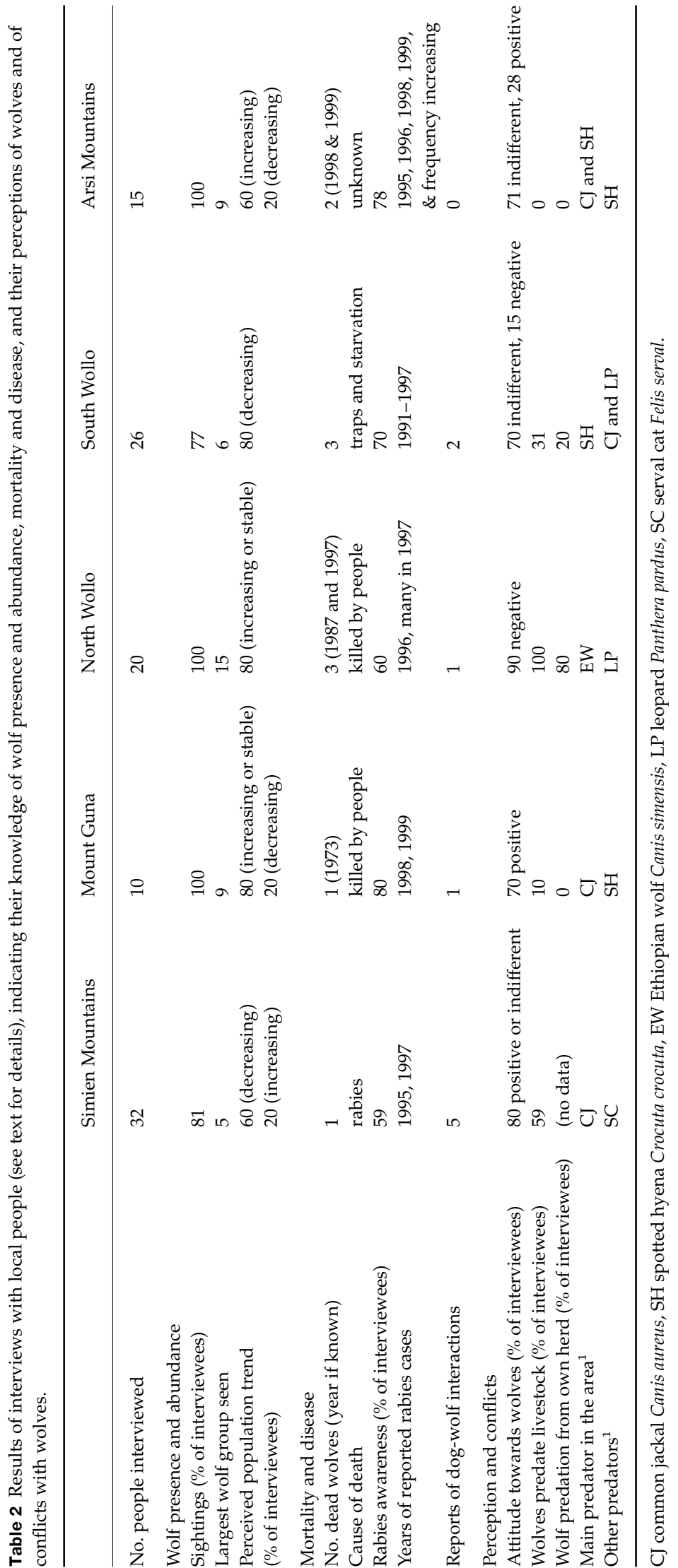

(C) $2003 \mathrm{FFI}$, Oryx, 37(1), 62-71 
Some reported negative attitudes because of livestock predation, but only a third reported livestock losses to wolves; spotted hyaenas Crocuta crocuta were considered the main predators in all areas.

\section{Mount Choke}

Available wolf habitat in Mount Choke was in a single patch limited by escarpments and agricultural fields at $3,700 \mathrm{~m}$ (Fig. 1e). No sign of wolves or their activity were recorded. Interviews with local people indicated that extinction might have occurred several decades ago, because even the oldest respondents did not remember having ever seen wolves. Common jackals were frequently observed.

\section{Gosh Meda}

With only $20 \mathrm{~km}^{2}$ of suitable wolf habitat remaining, this was the smallest AU (Table 1), limited to the east by the escarpments of the Rift Valley, but otherwise surrounded by recently ploughed fields and human settlements up to $3,700 \mathrm{~m}$. No sign of wolves or their activity were recorded. Interviewees indicated wolves were common as recently as 10 years ago, but were no longer resident in the area. There were reports of sporadic sightings of single wolves in 1992, 1996 and January 1999. Reasons for the decline were not known. Local people believed that wolves bring good luck and forecast years of good crops. Killings were reportedly infrequent in the past, and wolf predation on livestock was not perceived as a serious conflict. Common jackals were encountered and were reported to have extended into the area, where they are considered the main predator of livestock.

\section{Arsi Mountains}

The Arsi highlands comprised $870 \mathrm{~km}^{2}$ of suitable wolf habitat, the largest AU after Bale (Table 1). Around $50 \mathrm{~km}^{2}$ formed part of the Bora Luku Hunting Block. The lower boundary to wolf habitat were cultivated fields at 3,200-3,400 m (3,700 m in Mount Kaka) or in parts the natural lower limit of ericaceous heathlands. The remaining habitat was distributed across the extensive Galama range, Mount Chilalo, a lower saddle, called Chelelaka, connecting both, and an additional patch to the south in Mount Kaka (Fig. 1h). A broad band of extensively burnt ericaceous heathlands surrounded better quality patches for wolves at higher altitudes. Wolves and wolf signs were sighted in all areas, but more frequently in Galama. The average sightings per $\mathrm{km}$ were second only to that recorded in North Wollo (Fig. 2). All interviewees had seen wolves; the majority believed that they were breeding well and recovering from past persecution, but a few perceived that numbers were declining because of recent agricultural expansion (Table 2). Indifference and lack of conflicts were alleged to be due to the fact that people and livestock in Arsi used the high altitude pastures only seasonally. The main predators of livestock were common jackals and spotted hyaenas.

\section{Comparative analysis of habitats and populations}

The habitat currently available for wolves occupied less than half of the regions' land above 3,200 m (Table 1). Of the approximately $3,000 \mathrm{~km}^{2}$ left, $40 \%$ was under a certain degree of protection, but only c. $200 \mathrm{~km}^{2}$ in areas other than the Bale Mountains National Park. Including Menz and Bale (Figs 1f \& 1i), suitable wolf habitat exists in nine AUs, of which Mount Choke and Gosh Meda were unoccupied by wolves.

AUs differed in their size, spatial structure and proportion of habitat lost (Table 1). All AUs north of the Rift Valley, with the exception of Menz, contained less than a third of their potential wolf habitat. Similarly the lower boundary of wolf ranges tended to occur at consistently higher altitude in the north, following a human density cline from south to north (Statistical Authority, 1998) (Fig. 3); the altitudinal upper limit of cultivated fields increased linearly with decreasing latitude of AUs $\left(R^{2}=0.75 ; F=18.12\right.$, d.f. $\left.=6, \mathrm{P}=0.005\right)$. The altitudinal pattern of wolf habitat distribution indicated that areas below $3,700 \mathrm{~m}$ are particularly vulnerable to further habitat loss because of agricultural expansion. The local extinctions in Mount Choke and Gosh Meda were in relatively low-lying ranges.

Wolf population estimates were based on the extent of habitat available. Estimates tended to be larger in larger AUs, but a high proportion of 'good' to 'marginal' habitat in Menz gave a relatively high population estimate for such a small AU (Table 3). With the exception of Arsi and Simien, all other populations were estimated at $<25$ individuals. These conservative estimates appeared more appropiate for Simien and South Wollo, where wolf abundance was relatively low, but wolf numbers in North Wollo, Mount Guna and possibly Arsi may have been underestimated. In the case of Arsi, however, it was unclear weather resident wolves used all marginal habitat in the vast ericaceous heathlands.

\section{Discussion}

The surveys confirmed the existence of seven isolated Ethiopian wolf populations, and described two new populations, in South Wollo and North Wollo, the latter previously thought to be extinct, and with only a historical 


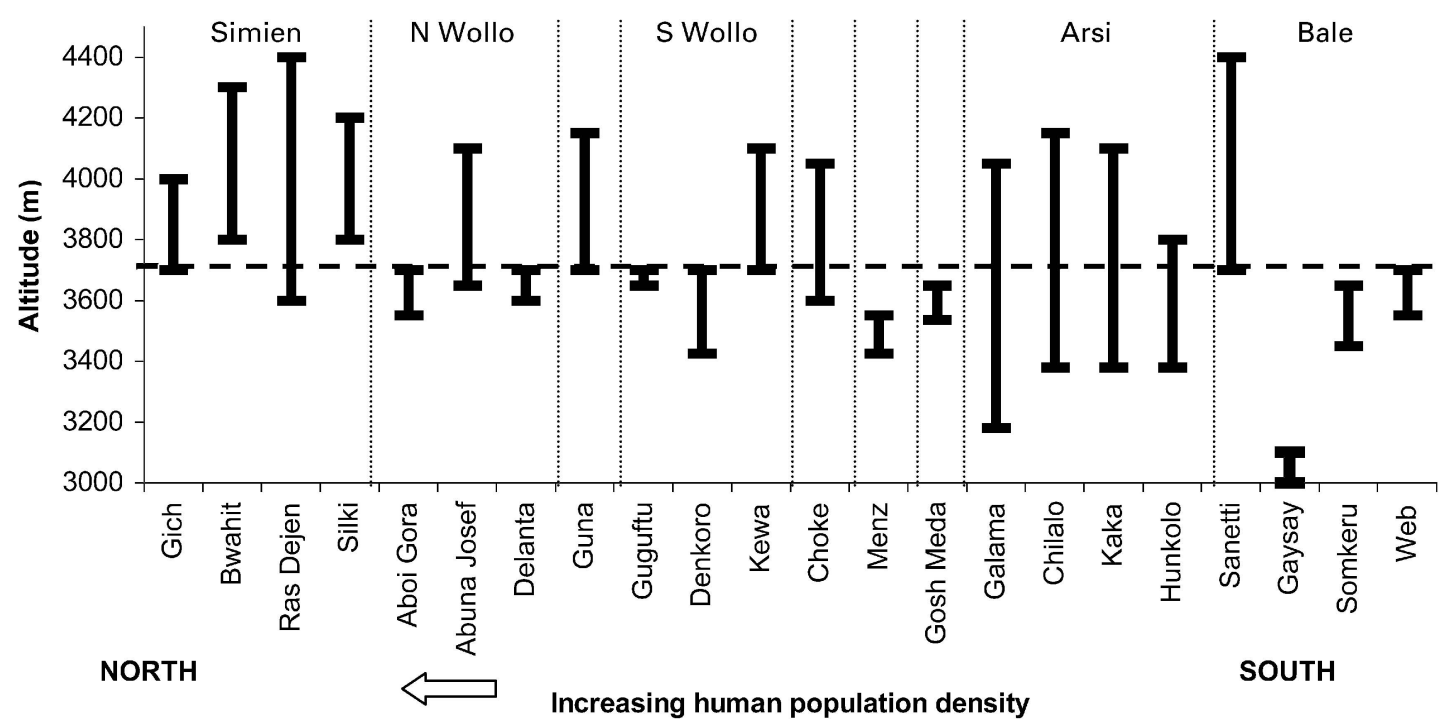

Fig. 3 Current altitudinal distribution of Ethiopian wolf habitats. Bars represent the altitudinal range of remaining suitable habitat in each area surveyed and in the Bale Mountains. The dashed line at 3,700 m indicates the approximate limit of sustainable agriculture in Ethiopia.

Table 3 Estimates of Ethiopian wolf populations in Afroalpine units north and south of the Rift Valley. Estimates were calculated by extrapolating the range of wolf densities from Bale to the areal extent of habitat categories (see text for details).

\begin{tabular}{|c|c|c|c|}
\hline \multirow[b]{2}{*}{ Afroalpine Unit } & \multicolumn{2}{|c|}{ Habitat types $\left(\mathrm{km}^{2}\right)$} & \multirow[b]{2}{*}{ Population estimate } \\
\hline & 'good' & 'marginal' & \\
\hline \multicolumn{4}{|l|}{ North of Rift Valley } \\
\hline Simien Mountains & 132 & 142 & $40-54$ \\
\hline Mt Guna & 22 & 29 & $7-10$ \\
\hline Mt Choke & 46 & 88 & extinct \\
\hline North Wollo & 46 & 94 & $19-23$ \\
\hline South Wollo & 21 & 122 & $16-19$ \\
\hline Menz $^{1}$ & 59 & 53 & $17-23$ \\
\hline Gosh Meda & 8 & 13 & extinct \\
\hline \multicolumn{4}{|l|}{ South of Rift Valley } \\
\hline Arsi Mountains & 144 & 646 & $93-108$ \\
\hline Bale Mountains ${ }^{2}$ & - & - & 250 \\
\hline Total & & & $442-487$ \\
\hline
\end{tabular}

${ }^{1}$ Habitat areas from recently updated maps.

${ }^{2}$ Most recent estimate of Bale's population (from Sillero-Zubiri et al., 2000).

record from 1862 (Gottelli \& Sillero-Zubiri, 1992). The study also confirmed the persistence of populations on Mount Guna, provided the first comprehensive survey of the Simien massif, and demonstrated that the Arsi population was more secure than previously thought (Malcolm \& Sillero-Zubiri, 1997). The study recorded the extinctions of the populations on Mount Choke and Gosh Meda; the last sightings on Mount Choke where in
1932 (Yalden, et al., 1980), and Gosh Meda had last been visited in 1989, when wolves were still present despite a dense human population (Gottelli \& Sillero-Zubiri, 1990).

The finding of resident wolves in most of the remaining suitable habitat, and their persistence in small Afroalpine pockets suggests that the species has some resilience to fragmentation and the effects of small population sizes. But with the exception of Bale and possibly Arsi, all populations are small, estimated to contain $<50$ individuals, and some $<25$. Although these estimates are based on habitat availability they clearly indicate the small size of some of the populations, which makes them susceptible to extinction from deterministic and stochastic factors (Soulé, 1987).

The Ethiopian wolf is a rare species under considerable pressure. The key to its survival resides in the security of its habitat and the isolation of populations from the adverse impacts of people, livestock and domestic dogs. Habitat protection to prevent or reduce further habitat loss would reduce the risk of extinction, in particular for those populations in small areas and at lower altitudes (e.g. Menz, Aboi Gara and Delanta). Conservation initiatives at regional and local community level, such as ones currently in place in Denkoro and Menz, are an alternative option to the traditional approach of habitat protection in national parks.

Rabies appears to be a threat in all surveyed areas, with cases reported in domestic dogs, livestock and wildlife, including one Ethiopian wolf (Table 2), a finding corroborated by a more extensive questionnaire in several areas (K. Laurenson, unpub. data). Diseases transmitted from domestic dogs have had devastating 
effects on wolves in Bale, and rabies is considered to be the main short-term threat to the persistence of all populations (Sillero-Zubiri et al., 1996; Laurenson et al., 1997, Haydon et al., in press). A large-scale vaccination programme of domestic dogs is ongoing in Bale (SilleroZubiri, 2000), and was recently extended to other populations in northern Ethiopia (Stuart Williams, pers. comm.).

Conservation actions to minimize threats such as persecution, loss of habitat due to road construction and commercial sheep farming, would require a close monitoring of those populations most vulnerable to these specific threats. In general, contacts and conflicts between wolves and humans are bound to increase with increasing human density and habitat fragmentation. In the heavily populated northern highlands, for example, livestock graze on high altitude pastures all year round and livestock predation by wolves has resulted in negative attitudes amongst the local people, and sporadic killings, at least in South Wollo. Persecution, however, has been more common in the past, because of indiscriminate wildlife killings during the period of civil war in the 1980s and early 1990s; a phenomenon also documented in Bale and Menz in the early 90's (Sillero-Zubiri et al., 1996; Ashenafi, 2001). Hybridization between dogs and wolves seems to be restricted to a single population in Bale (Gottelli et al., 1994), because no other cases of hybridization either in the past or recently have been reported or were discovered during the surveys.

This study provides an evaluation of the status and distribution of Ethiopian wolves that is crucial for the planning of future conservation activities for the species. It confirms the importance of Bale for the long-term persistence of the species, but also highlights the need for conservation actions to be extended to other extant populations. The population in South Wollo is a good candidate for a priority area for conservation because it sustains wolves at relatively high density yet it is threatened in many diverse ways. Following the outcome of these surveys and a workshop in Bale (SilleroZubiri et al., 2000), the Ethiopian Wolf Conservation Programme was expanded to other populations in the north, widening the use of the Ethiopian wolf as a flagship species for the conservation of Ethiopia's unique Afroalpine ecosystem.

\section{Acknowledgements}

I wish to thank all Regional, Zonal and Wareda Authorities that helped and cooperated in conducting the surveys, the Ethiopian Wildife Conservation Organization, the Simien Mountains National Park staff and Ethiopian Rift Valley Safaris. I am specialy grateful to all the people that participated in the field activities, including Kassaw Aragaw, Neville Ash, Zelealem Ashefani, Malku Baleta, Kassim Biftu, Tesfaye Dabele, Dinku Degu, Derbie Deksios, Edriss Ebu, Wolde Gebremedin, Kashay Girmay, Alo Hussein, Karen Laurenson, Mohabu, Scott Newey, Fekadu Shiferaw, Claudio Sillero-Zubiri, Mullat Tegegn, Geshu Teshome, Minda Teshome, Simon Thirgood and Gobeze Wolle. I thank four anonymous reviewers and Claudio SilleroZubiri, Stuart Williams, Karen Laurenson, Ruth Feber and Laura Bonesi for their comments on preliminary versions of the manuscript. This work was funded by a National Geographical Society grant to Claudio SilleroZubiri and Karen Laurenson, with additional support from the Born Free Foundation, Bernd Thies Foundation and Welcome Trust.

\section{References}

Ash, N. (2000) Report on the work of the Ethiopian Wolf Conservation Programme in Amhara Region, 2000. Unpublished Report, Ethiopian Wolf Conservation Programme, Ethiopia.

Ashenafi, Z.T. (2001) Common property resource management of an Afro-alpine habitat: supporting a population of the critically endangered Ethiopian wolf (Canis simensis). DPhil thesis, University of Kent, Canterbury, UK.

Gottelli, D. \& Sillero-Zubiri, C. (1990) The Simien Jackal, Ecology and Conservation. Unpublished Report, Bale Mountains Research Project, Ethiopia.

Gottelli, D. \& Sillero-Zubiri, C. (1992). The Ethiopian wolf - an endangered endemic canid. Oryx, 26, 205-214.

Gottelli, D., Sillero-Zubiri, C., Applebaum, G.D., Roy, M.S., Girman, D.J., Garcia-Moreno, J., Ostranders, E.A. \& Wayne, R.K. (1994) Molecular genetics of the most endangered canid: the Ethiopian wolf Canis simensis. Molecular Ecology, 3, 301-312.

Haydon, D.T., Laurenson, M.K. \& Sillero-Zubiri, C. (2002) Integrating epidemiology into population viability analysis: managing the risk posed by rabies and canine distemper to the Ethiopian wolf. Conservation Biology, 16, 1372-1385.

IUCN (2002) 2002 IUCN Red List of Threatened Species. Http:/ / www.redlist.org [accessed 23 October 2002].

Laurenson, M.K., Shiferaw, F. \& Sillero-Zubiri, C. (1997) Disease, domestic dogs and the Ethiopian wolf: the current situation. In The Ethiopian Wolf. Status Survey and Conservation Action Plan. (eds C. Sillero-Zubiri \& D.W. Macdonald), pp 32-42. IUCN, Gland, Switzerland \& Cambridge, UK. Malcolm, J.R. \& Sillero-Zubiri, C. (1997) The Ethiopian wolf: distribution and population status. In The Ethiopian Wolf. Status Survey and Conservation Action Plan. (eds C. SilleroZubiri \& D.W. Macdonald), pp 12-25. IUCN, Gland, Switzerland \& Cambridge, UK.

Marino, J., Laurenson, M.K. \& Sillero-Zubiri, C. (1999) Distribution of the Ethiopian wolf (Canis simensis): Population Status and Habitat Analysis. Unpublished Report, Ethiopian Wolf Conservation Programme \& National Geographic Society, Ethiopia. 
Morrison, M., Marcot, B. \& Mannan, R. (eds) (1998) Wildlifehabitat Relationships: Concepts and Applications. The University of Wisconsin Press, Wisconsin, USA.

Miehe, G. \& Miehe, S. (1993) On the physiognomy and floristic differentiation of ericaceous vegetation in the Bale Mountains, SE Ethiopia. Opera Botanica, 121, 85-112.

Sillero-Zubiri, C. (2000). Ethiopian wolf (Canis simensis). In Endangered Animals: A Reference Guide to Conflicting Issues (eds R.P. Reading \& B. Miller), pp 95-100. Greenwood Press, Westport, USA.

Sillero-Zubiri, C. \& Gottelli, D. (1995) Spatial organization in the Ethiopian wolf Canis simensis: Large packs and small stable home ranges. Journal of Zoology London, 237, 65-81.

Sillero-Zubiri, C., King, A.A. \& Macdonald, D.W. (1996) Rabies and mortality in Ethiopian wolves (Canis simensis). Journal of Wildlife Diseases, 32, 80-86.

Sillero-Zubiri, C. \& Macdonald, D.W. (1997) The Ethiopian Wolf: Status Survey and Conservation Action Plan. IUCN, Gland, Switzerland \& Cambridge, UK.

Sillero-Zubiri, C., Tattersall, F.H. \& Macdonald, D.W. (1995a) Bale mountains rodent communities and their relevance to the Ethiopian wolf (Canis simensis). African Journal of Ecology, $33,301-320$.

Sillero-Zubiri, C., Tattersall, F.H. \& Macdonald, D.W. (1995b) Habitat selection and daily activity of giant molerats Tachyoryctes macrocephalus: Significance to the Ethiopian wolf Canis simensis in the Afroalpine ecosystem. Biological Conservation, 72, 77-84.
Sillero-Zubiri, C., Malcolm, J.R., Williams, S., Marino, J., Ashenafi, Z.T., Laurenson, M.K., Gottelli, D., Hood, A., Macdonald, D.W., Wildt, D. \& Ellis, S. (2000) Ethiopian Wolf Conservation Strategy Workshop. Unpublished Report, IUCN/SSC Canid Specialist Group and Conservation Breeding Specialist Group, Dinsho, Ethiopia.

Soulé, M.E. (ed.) (1987) Viable Populations for Conservation. Cambridge University Press, Cambridge, UK.

Statistical Authority (1998) Statistical Abstracts of Ethiopia: Analytical Report. Unpublished Report, Statistical Authority, Addis Ababa, Ethiopia.

Yalden, D. \& Largen, M. (1992) The endemic mammals of Ethiopia. Mammal Review, 22, 115-150.

Yalden, D., Largen, M. \& Kock, D. (1980) Catalogue of the mammals of Ethiopia. 4. Carnivora. Monitore Zoologico Italiano NS Supplemento, 169-272.

\section{Biographical sketch}

Jorgelina Marino has studied native forests in Argentine Patagonia, patterns of large mammal distribution in Senegal's Sahel, and was the resident ecologist of the Ethiopian Wolf Conservation Programme for 1997-2000. She is now studying the use of spatial and landscape ecology to tackle wildlife conservation issues. 